\title{
Morphometric study of the ciliary ganglion and its pertinent intraorbital procedure
}

\author{
L. Tesapirat' ${ }^{1}$ S. Jariyakosol ${ }^{2}{ }^{3}$, V. Chentanez ${ }^{1}$ \\ ${ }^{1}$ Department of Anatomy, Faculty of Medicine, Chulalongkorn University, Bangkok, Thailand \\ 2Department of Ophthalmology, Faculty of Medicine, Chulalongkorn University, Bangkok, Thailand \\ ${ }^{3}$ Ophthalmology Department, King Chulalongkorn Memorial Hospital, Thai Red Cross Society, Bangkok, Thailand
}

[Received: 20 September 2019; Accepted: 12 October 2019]

Background: Ciliary ganglion (CG) can be easily injured without notice in many intraorbital procedures. Surgical procedures approaching the lateral side of the orbit are at risk of CG injury which results in transient mydriasis and tonic pupil. This study aims to focus on the morphometric study of the CG which is pertinent to intraoperative procedure.

Materials and methods: Forty embalmed cadaveric globes were dissected to observe the location, shape and size of $C G$, characteristics and number of roots reaching $C G$, number of short ciliary nerve in the orbit. Distances from CG to posterior end of globe, optic nerve, lateral rectus muscle and its scleral insertion were measured. Results: Ciliary ganglion was located between optic nerve and lateral rectus in every case. Its shape could be oval, round and irregular. Mean width of CG was $2.24 \mathrm{~mm}$ and mean length was $3.50 \mathrm{~mm}$. Concerning the roots, all 3 roots were present in 29 (72.5\%) cases. Absence of motor root was found in 7 (17.5\%) cases. Absence of sympathetic root was found in $4(5 \%)$ cases. The number of motor root could be 1,2 and also 3 roots. Three motor roots were found in 1 case which originated from nerve to inferior oblique muscle. Only one sensory root was found in every specimen. One sympathetic root could be observed in most of the specimens and 6-14 short ciliary nerves were found. Mean distances from CG to posterior end of globe, optic nerve, lateral rectus muscle and its scleral insertion were $16.04 \mathrm{~mm}, 1.47 \mathrm{~mm}, 2.88 \mathrm{~mm}$, and $31.53 \mathrm{~mm}$, respectively.

Conclusions: This study described the characteristic of CG, number of its nerve root and some measurements relevant to intraorbital procedures in Asian population. Moreover, a new parameter was the distance between CG and scleral insertion of the lateral rectus muscle. This parameter should be considered when performing operation involved the lateral rectus muscle and BTX-A injection to lateral rectus muscle to reduce CG injury. (Folia Morphol 2020; 79, 3: 438-444)

Key words: ciliary ganglion, mydriasis, tonic pupil

\section{INTRODUCTION}

Ciliary ganglion (CG) is approximately $3 \mathrm{~mm}$ in size and easily injured without notice in many procedures
$[3-5,9,15,16,18,21,22,29]$. It lies posterolateral in the orbit, so surgical procedures approaching the lateral side of the orbit such as lateral orbitotomy, infero-

Address for correspondence: V. Chentanez, MD, PhD, Department of Anatomy, Faculty of Medicine, Chulalongkorn University, Bangkok 10330, Thailand, tel: 66-860701084, e-mail: fmedvct@gmail.com 
lateral endoscopic orbital approach (IL-EOA), transmaxillary approach to the orbit, lateral approach of optic nerve sheath fenestration and inferior oblique muscle surgery are at risk of $C G$ injury $[5,8,10,12,20,28]$. Therefore, morphometric study of CG is essential for surgeons in order for preferable results during operative procedures including the distance between CG and optic nerve, $\mathrm{CG}$ and the lateral rectus muscle, and $\mathrm{CG}$ and posterior end of the globe. Botulinum toxin $\mathrm{A}$ (BTX-A) injection is used for treatment of strabismus, blepharospasm and for cosmetic purposes. There are some reports of transient mydriasis or tonic pupil as a complication of these procedures $[1,6,14]$. The cause of transient mydriasis is either from pharmacological blockage of cholinergic activity by means of trans-scleral diffusion or ciliary artery perfusion, if the injection is superficial to the muscle or from direct injury occurs at the level of CG in the event that injection is too deep $[1,6,14]$.

A few studies of microsurgical anatomy of CG were reported in different ethnicities with a small sample size $[13,16,26]$. Asian population has not been studied. Moreover, the distance from CG to sclera insertion of lateral rectus muscle which may be beneficial for botulinum toxin injection has not been investigated. Therefore, the aim of this study was to focus on the morphometric study of CG and its application to intraorbital procedures in Asian population.

\section{MATERIALS AND METHODS}

Forty globes (36 right globes, 4 left globes) from 40 Thai adult embalmed cadavers ( 24 males; $60 \%$ and 16 females; $40 \%$ ) were dissected under $2.5 \times$ magnifying loupe. All cadavers were embalmed the same way with $10 \%$ formalin, and did not suffer from any disease affecting orbit. The mean \pm standard deviation age of all cadavers was $73.85 \pm 12.48$ years (age range 52-93 years). The whole orbital content with complete periorbita were taken off from the bony orbital cavity and then fixed with $10 \%$ formalin. Non-drying polymer clay was used to mould medial and lateral walls and also floor of orbit of each specimen to stabilise the orbital structure in its position for accuracy of measurement. The periorbital, orbital fat, frontal nerve and muscles which were located superior to optic nerve were dissected carefully, avoiding medial and lateral structure distortion for clear exposure of muscles and nerves. Nasociliary nerve and branches of oculomotor nerves were identified and dissected carefully to track roots of the CG. Orbital fat was delicately removed so as to obviate the CG, its roots and short ciliary nerves. The location and shape of CG was observed and recorded. The size of $\mathrm{CG}$ was determined by measuring the length from anterior edge to posterior edge of CG in axis parallel to the optic nerve and the width between superior edge and inferior edge, which was perpendicular to the optic nerve axis were measured. The shortest distance between the CG and the lateral rectus muscle were then measured. After finishing the first measurement, other structures were carefully dissected including posterior end of the globe, scleral insertion of the lateral rectus muscle, optic nerve, roots of CG and the short ciliary nerves. Measurement of distances from CG to posterior end of the globe, scleral insertion of the lateral rectus muscle, optic nerve was obtained. The number of sensory, motor and sympathetic roots of the CG was evaluated. The origin of motor root was identified. Moreover, the number of short ciliary nerves was counted. The same investigator (L.T.) made all measurements by a standardised digital Vernier calliper (BakerTM EC-10; range 6"/150 mm, resolution $0.0005^{\prime \prime} / 0.01 \mathrm{~mm}$ ) three times per each datum in a micrometre.

\section{Statistical analysis}

Statistical analysis was performed by IBM SPSS Statistics Base version 22.0. Mean and standard deviation (SD) of each parameter was obtained. Intra-observer reliability was calculated for each parameter and the least intra-observer intraclass correlation coefficient among our parameters was 0.962 .

\section{Ethical consideration}

This cadaveric study has been approved by the Institutional Review Board (IRB), Faculty of Medicine, Chulalongkorn University (IRB NO.161/62).

\section{RESULTS}

Location, shape, size and distance from CG to posterior end of globe, optic nerve, lateral rectus muscle and its scleral insertion

Ciliary ganglion could be identified in all 40 cases. It was located between lateral rectus and optic nerve. Its shape could be oval, round and irregular. The mean length \pm SD from anterior edge to posterior edge of CG in axis parallel to the optic nerve was $3.50 \pm$ $\pm 0.73 \mathrm{~mm}$ (range: $1.70-5.21 \mathrm{~mm}$ ). The mean width \pm SD between superior edge and inferior edge, which was perpendicular to the optic nerve axis, was $2.24 \pm$ $\pm 0.57 \mathrm{~mm}$ (range: $1.39-3.95 \mathrm{~mm}$ ). The mean dis- 
Table 1. Distance from the ciliary ganglion (CG) to posterior end of the globe, scleral insertion of the lateral rectus muscle (LR) and optic nerve

\begin{tabular}{lcccc}
\hline Distance from CG [mm] & To posterior end of globe & To LR (perpendicular) & To LR's insertion on sclera & To optic nerve \\
\hline Mean \pm standard deviation & $16.04 \pm 2.83$ & $2.88 \pm 0.66$ & $31.53 \pm 3.67$ & $1.47 \pm 0.40$ \\
(range: min-max) & $(9.18-24.60)$ & $(1.86-4.49)$ & $(23.27-40.55)$ & $(0.81-2.44)$ \\
\hline
\end{tabular}
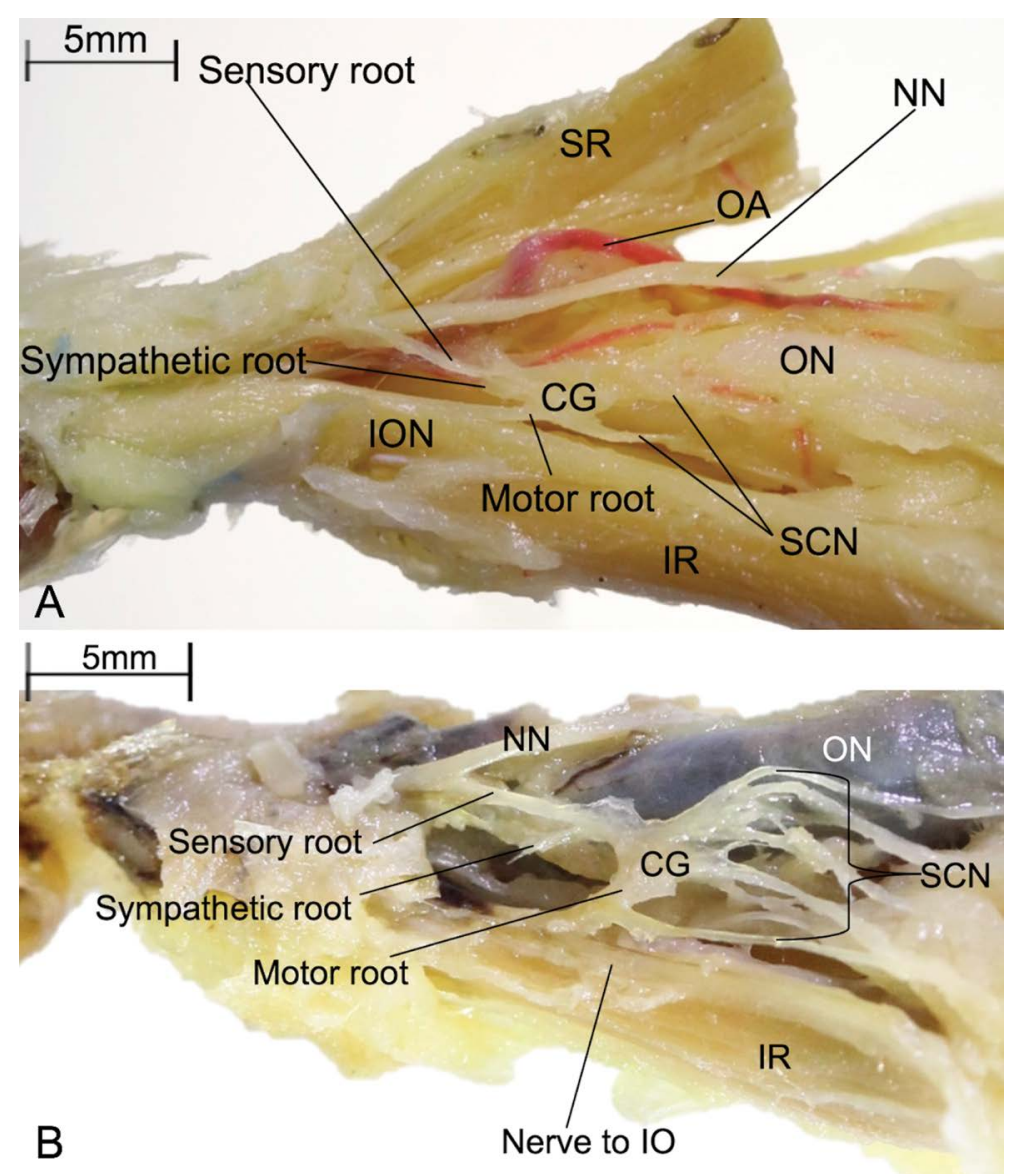

Figure 1. Ciliary ganglion (CG) with one motor root (parasympathetic root); A. Branching from inferior division of oculomotor nerve; B. Branching from nerve to inferior oblique muscle; 10 inferior oblique muscle; ION — inferior division of oculomotor nerve; IR — inferior rectus muscle; $\mathrm{NN}$ - nasociliary nerve; $\mathrm{OA}$ - ophthalmic artery; $\mathrm{ON}$ - optic nerve; SCN — short ciliary nerve; $S R$ - superior rectus muscle.

tances from CG to posterior end of the globe, scleral insertion of the lateral rectus muscle and optic nerve are depicted in Table 1.

\section{Roots of CG}

Motor, sensory and sympathetic roots were identified in each CG. All 3 roots were present in 29 $(72.50 \%)$ cases. Absence of motor root was found in $7(17.5 \%)$ cases. Absence of sympathetic root was found in $4(10 \%)$ cases. Only one sensory root was found in every specimen.

Motor (parasympathetic) root of CG rose from either nerve to inferior oblique muscle or inferior division of oculomotor nerve. Motor root was the largest root of CG and reached CG in infero-posterior angle. This root was located most inferior comparing to other roots. There were zero, one, two and three motor root(s) (Figs. 1-4). The most frequent number was one motor root (25 cases, $62.5 \%$ ). Three motor roots were found in one case which originated from nerve to inferior oblique muscle (Fig. 3). Absence of motor root was found in 7 (17.5\%) cases. The ganglion in these cases lied on either nerve to inferior oblique muscle (5 cases) or inferior division of oculomotor nerve ( 2 cases) (Fig. 4). Detail of number and origin of motor root are described in Table 2 .

The sympathetic root reached CG between motor and sensory roots (Fig. 1). It was very thin, delicate and hard to identify. According to the observation, $4(10 \%)$ out of 40 specimens could not identify sympathetic root and the other 36 (90\%) specimens contained one sympathetic root.

The nasociliary nerve diverged from ophthalmic nerve and passed through annular tendon. It gave 

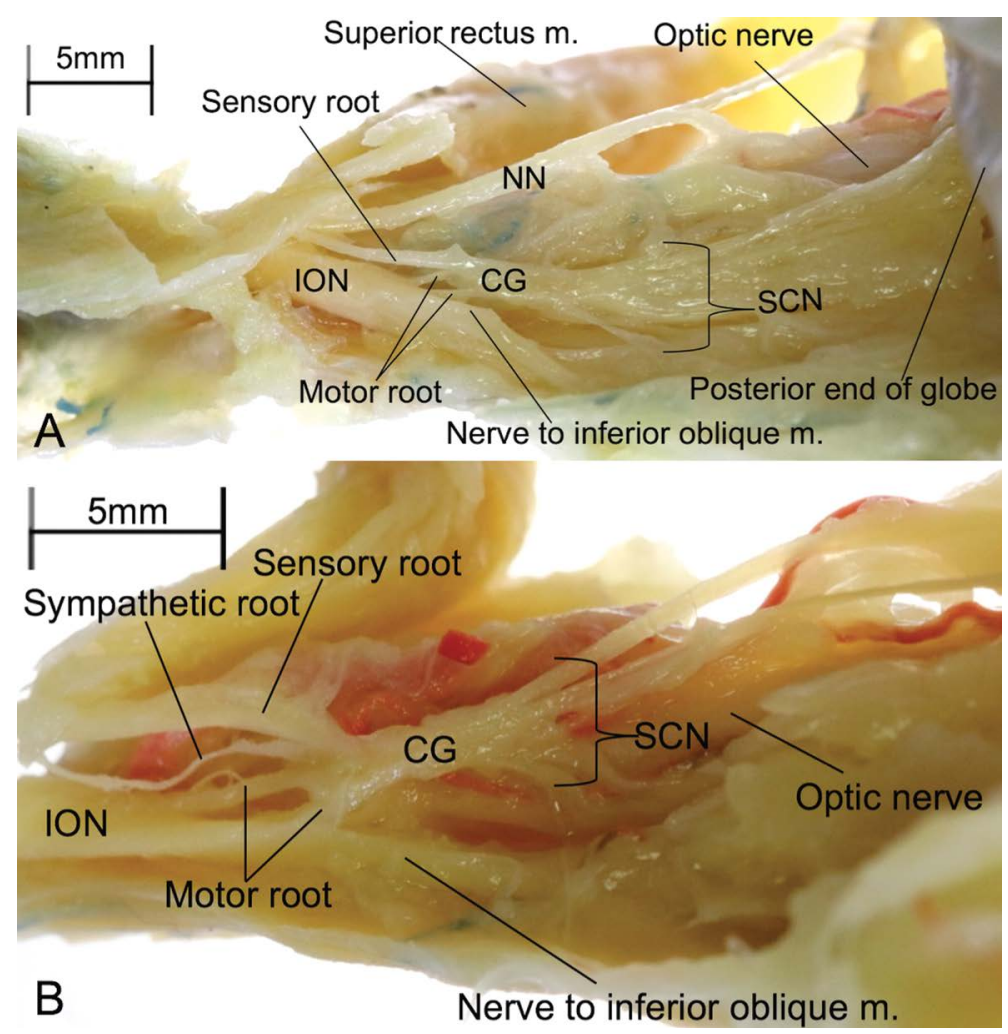

Figure 2. Ciliary ganglion (CG) with two motor roots; $\mathbf{A}$. Both roots branching from nerve to inferior oblique muscle; B. One root branching from inferior division of oculomotor nerve and the other branching from nerve to inferior oblique muscle; ION - inferior division of oculomotor nerve; $\mathrm{NN}$ - nasociliary nerve; $\mathrm{SCN}$ - short ciliary nerve.

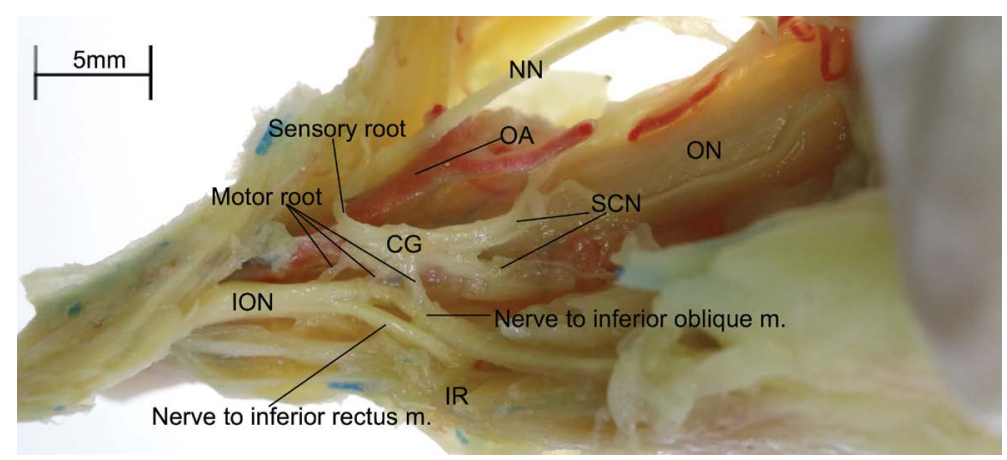

Figure 3. Ciliary ganglion (CG) with three motor roots branching from nerve to inferior oblique muscle; ION - inferior division of oculomotor nerve; IR - inferior rectus muscle; $\mathrm{NN}$ - nasociliary nerve; $\mathrm{OA}$ - ophthalmic artery; $\mathrm{ON}$ - optic nerve; $\mathrm{SCN}$ - short ciliary nerve.

off many long ciliary nerves which pierced the sclera to enter the globe and also branched sensory root heading to enter CG in supero-posterior angle. It crossed the optic nerve where the ophthalmic artery and superior ophthalmic vein cross. All of the 40 specimens contained one sensory root. The sensory root was the first to be identified on account of the most superior position and branching from the prominent nasociliary nerve (Figs. 1-4).

\section{Short ciliary nerves}

Short ciliary nerves were the branches from CG (Figs. 1-4). They passed through tenon capsule and the globe to convey sensory signal from cornea, iris and ciliary body. They always came to the eyeball at lateral part. As stated by this finding, the mode number of short ciliary nerve was 9 nerves (range: 6-14 nerves) which was found in 7 (17.5\%) samples.

\section{DISCUSSION}

Knowledge of CG anatomy and morphometric study between surrounding structures is important for surgeons in performing intraorbital procedures [5]. High-resolution magnetic resonance imaging could be used to demonstrate CG in vivo, but CG always escaped notice during surgery [7]. Schacher (1701) was the first to describe CG in the orbit [26]. Since then, there have been few studies about CG, especially morphometric studies between it and its surrounding structures.

In Asian population from this study, the width and length of CG were 2.24 and $3.50 \mathrm{~mm}$, respectively and it was located in orbital apex, posterolateral in the 


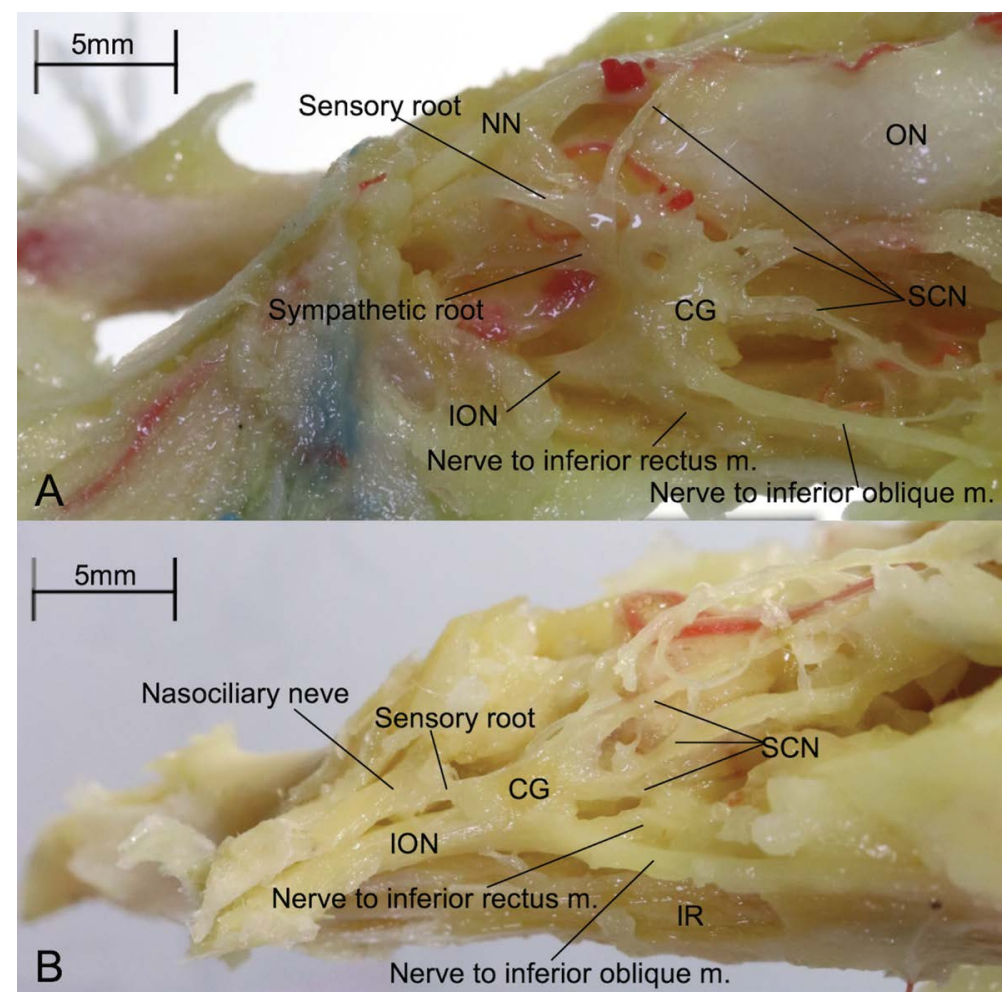

Figure 4. Ciliary ganglion (CG) without motor root; A. CG lying on nerve to inferior oblique muscle; B. CG directly attached on inferior division of oculomotor nerve; ION - inferior division of oculomotor nerve; IR - inferior rectus muscle; $\mathrm{NN}$ - nasociliary nerve; $\mathrm{ON}$ — optic nerve; SCN — short ciliary nerve.
Table 2. Number and origin of motor root(s)

\begin{tabular}{|c|c|c|}
\hline $\begin{array}{l}\text { Number } \\
\text { of motor } \\
\text { root }\end{array}$ & Origin of motor root(s) & $\begin{array}{c}\text { Number of } \\
\text { specimens (\%); } \\
n=40\end{array}$ \\
\hline 1 & From nerve to inferior oblique muscle & $22(55 \%)$ \\
\hline 1 & $\begin{array}{c}\text { From inferior division of oculomotor } \\
\text { nerve }\end{array}$ & $3(7.5 \%)$ \\
\hline 2 & From nerve to inferior oblique muscle & $4(10 \%)$ \\
\hline 2 & $\begin{array}{l}\text { One root from inferior division of } \\
\text { oculomotor nerve } \\
\text { The other one root from nerve to } \\
\text { inferior oblique muscle }\end{array}$ & $3(7.5 \%)$ \\
\hline 3 & From nerve to inferior oblique muscle & $1(2.5 \%)$ \\
\hline 0 & $\begin{array}{l}\text { Lying on nerve to inferior oblique } \\
\text { muscle }\end{array}$ & $5(12.5 \%)$ \\
\hline 0 & $\begin{array}{l}\text { Lying on inferior division of } \\
\text { oculomotor nerve }\end{array}$ & $2(5 \%)$ \\
\hline
\end{tabular}

globe, lateral to optic nerve and medial to lateral rectus muscle. The size and position of $\mathrm{CG}$ did not differ from the literature. Positional variation of CG was reported in one case report, where, CG was placed between medial rectus and optic nerve [10]. The distance between CG and surrounding structures, which are considered useful during intraorbital procedures, were measured in Asian population in our study. Comparing with the study in Turkey which their material and methods were comparable to this study [16], distance from CG to lateral rectus muscle was shorter, but the distance between the posterior end of globe and anterior edge of CG was longer in our study. Therefore, the CG in Asians might locate very close to the lateral rectus and near the orbital apex more than the Turkish. These differences may be due to disparate ethnicities. This result can be used for estimating the location of CG in the orbital apex. Because of the location of CG was very close to lateral rectus in Asians, it could be easily injured from retraction of the lateral rectus muscle during operation of lateral orbitotomy $[2,3,8,11,12,18]$. Therefore, awareness of CG-lateral rectus and CG-posterior end of globe relationships should be considered especially in Asian population during this operation.

Optic nerve sheath fenestration (ONSF) is commonly indicated in optic neuropathy in the setting of raised intracranial pressure, especially in patients with severe progressive visual loss due to idiopathic intracranial hypertension [19]. There was a review about postoperative complications after ONSF in 15 studies (from 1985 to 2014). Many different approaches of ONSF were included, but tonic pupil complication was often found in the lateral orbitotomy approach. CG injury was suspected to have an association with tonic pupil complication $[9,28]$. As a result, the distance from optic nerve to $C G$ and also the distance between 
CG and lateral rectus muscle should be considered during ONSF operation via lateral approach. These study results are useful and applicable in this operation in Asian population.

Botulinum toxin type A injection into the antagonist muscle of the paretic muscle to decrease tone of antagonist muscle is used as one of strabismus treatment. Moreover, BTX-A is used for treatment of blepharospasm and cosmetic purpose. There are many studies that reported temporary mydriasis, tonic pupil and ptosis after BTX-A injection to periocular area and extraocular muscles, which commonly occur in lateral rectus muscle injection [1]. The hypothesized mechanism of tonic pupil after botulinum toxin injection into extraocular muscle and periocular area was pharmacological blockage of the cholinergic terminal in the iris either by way of trans-sclera diffusion or by ciliary artery perfusion, or direct injury at the parasympathetic pathway neural structures including CG and short ciliary nerves [6]. Because injection BTX-A into the lateral rectus muscle might cause CG injury, the distance from lateral rectus muscle insertion to CG in this study should be realised.

Ciliary ganglion is known to have three main branches including motor (parasympathetic), sympathetic, sensory roots, but this current study ascertains that there are some variations in disposition of roots. Parasympathetic fibres from the Edinger-Westphal nucleus played an important role in pupillary near response and pupillary light reflex. Disruption of parasympathetic pathway including injury to the nerve to inferior oblique muscle, CG and the short ciliary nerves results in mydriasis pupil and local typed tonic pupil. Tonic pupil is divided into three types composing of Adie tonic pupil, neuropathic tonic pupil and local tonic pupil [27]. The characteristics of tonic pupil are dilation of pupil; light near dissociation; segmental palsy of the iris sphincter; and denervation hypersensitivity to the dilute cholinergic agents [23]. Regarding this study, the motor (parasympathetic) root of CG was discovered into four dispositions, including three motor roots, two motor roots, one motor root and no motor root. The origin of motor root mentioned in this report (Table 2) has not been well described in any previous studies. Furthermore, CG with three motor roots has never been reported. All three roots branched out from nerve to inferior oblique muscle. CG that had no motor root lay on either nerve to inferior oblique muscle or inferior division of oculomotor nerve. This finding of no motor root went along with previous reports $[13,26]$. Hamel et al. (2012) [13] postulated that the absence of motor root might be due to the excess or default in the migration of neural crest cell along cranial nerve. The direct attachment of CG to inferior oblique muscle or inferior division of oculomotor nerve was also in accordance with easily injured CG from operation involving manipulation of inferior oblique muscle or disturbing nerve to inferior oblique muscle. There are few case reports of manipulation of inferior oblique muscle during medial orbital floor fracture reconstruction causing unilateral mydriasis [15, 21, 22]. Moreover, during inferior oblique muscle surgery as a treatment of strabismus, especially in denervation-extirpation, excessive traction on inferior oblique muscle can cause excessive traction and injure CG directly or indirectly via traction nerve to inferior oblique muscle [20].

The sympathetic fibres are formed by post ganglionic fibre from neurons located at the superior cervical ganglion. Postganglionic fibres leave superior cervical ganglion via internal and external carotid nerve, then form the carotid plexus around internal carotid artery [25]. The sympathetic root reaching CG comes from either directly from nervus caroticus internus and comes to the orbit via superior orbital fissure, or from plexus around the ophthalmic artery which is already in the orbit [25]. Several studies could not identify the sympathetic root reaching $C G$ in some of their specimens $[13,17,24,26]$. In this report, sympathetic root could not be found in 4 out of 40 specimens (10\%). Hamel et al. (2012) [13] reported the absence of sympathetic root in $20 \%$ of 20 cases. Johnson and Parkinston (1974) [17] believed that the sympathetic fibre joined the abducens nerve and is distributed with the branches of ophthalmic nerve.

Afferent sensory fibres from mostly cornea, iris and ciliary body were conveyed by short ciliary nerves and passed through CG and sensory root to travel by the nasociliary branch of ophthalmic nerve. It has been reported that the sensory root came from the nasociliary nerve and consisted of only one root $[5,13]$. According to this study, the sensory root was identified in all specimens and found only one root which came from the nasociliary nerve. No variation was observed.

\section{Limitations of study}

The limitation of this study was the absence of reporting of origin and pathway of sympathetic root and also intraorbital vessels. The specimens were from cadavers for medical student study; therefore, comparison between sides and genders was limited. 


\section{CONCLUSIONS}

Anatomical knowledge of CG and its surrounding structures is essential for surgeons to reduce CG injury as postoperative complication.CG and its afferent and efferent roots are in the orbital fat and always escaped notice because of its size and similar colour to fat. This morphometric study of CG and its surrounding structures is reported in Asian population. It is suspected that other ethnicities will yield different results. The mean distance between the CG and posterior end of the globe, optic nerve, lateral rectus muscle can be applied to orbital surgery to avoid CG injury. During operation involving lateral rectus muscle and botulinum toxin injection to the lateral rectus muscle as a treatment of strabismus, the mean distance between CG and the scleral insertion of the lateral rectus muscle, which was firstly described, should be considered to help decrease chances of tonic pupil.

\section{Acknowledgements}

The authors would like to show our regard and sincere appreciation to all those who have donated their bodies for medical study and research. Special thanks to the Department of Anatomy, Faculty of Medicine, Chulalongkorn University for venue and equipment in this study.

\section{REFERENCES}

1. Akkaya S, Kökcen HK, Atakan T. Unilateral transient mydriasis and ptosis after botulinum toxin injection for a cosmetic procedure. Clin Ophthalmol. 2015; 9: 313-315, doi: 10.2147/ OPTH.S76054, indexed in Pubmed: 25709394.

2. American Academy of Opthalmology. Orbit, eyelids, and lacrimal system.American Academy of Opthalmology, San Francisco 2015.

3. Arai H, Sato K, Katsuta T, et al. Lateral approach to intraorbital lesions: anatomic and surgical considerations. Neurosurgery. 1996; 39(6): 1157-62; discussion 1162, doi: 10.1097/00006123-199612000-00018, indexed in Pubmed: 8938770.

4. Blessing NW, Tse DT. Optic nerve sheath fenestration: a revised lateral approach for nerve access. Orbit. 2019; 38(2): 137-143, doi: 10.1080/01676830.2018.1452949, indexed in Pubmed: 29565728.

5. Bodker FS, Cytryn AS, Putterman AM, et al. Postoperative mydriasis after repair of orbital floor fracture. Am J Ophthalmol. 1993; 115(3): 372-375, doi: 10.1016/s00029394(14)73591-3, indexed in Pubmed: 8442499.

6. Christiansen SP, Chandler DL, Lee KA, et al. Tonic pupil after botulinum toxin-A injection for treatment of esotropia in children. J AAPOS. 2016; 20(1): 78-81, doi: 10.1016/j.jaapos.2015.09.011, indexed in Pubmed: 26917081.

7. Demer JL, Ortube MC, Engle EC, et al. High-resolution magnetic resonance imaging demonstrates abnormalities of motor nerves and extraocular muscles in patients with neuropathic strabismus. J AAPOS. 2006; 10(2): 135-142, doi: 10.1016/j. jaapos.2005.12.006, indexed in Pubmed: 16678748.

8. Düz B, Secer HI, Gonul E. Endoscopic approaches to the orbit: a cadaveric study. Minim Invasive Neurosurg. 2009; 52(3): 107-113, doi: 10.1055/s-0029-1220931, indexed in Pubmed: 19650012.
9. Gilbert AL, Chwalisz B, Mallery R. Complications of optic nerve sheath fenestration as a treatment for idiopathic intracranial hypertension. Semin Ophthalmol. 2018; 33(1): 36-41, doi: 10.1080/08820538.2017.1353810, indexed in Pubmed: 29420144.

10. Girijavallabhan V, Bhat KMR. Positional variation of the ciliary ganglion and its clinical relevance. Neuroanatomy. 2008; 7: 38-40.

11. Gönül E, Erdogan E, Düz B, et al. Transmaxillary approach to the orbit: an anatomic study. Neurosurgery. 2003; 53(4): 935-41; discussion 941, doi: 10.1227/01.neu.0000084164.22028.10, indexed in Pubmed: 14519225.

12. Gönül E, Timurkaynak E. Lateral approach to the orbit: an anatomical study. Neurosurg Rev. 1998; 21(2-3): 111-116, doi: 10.1007/BF02389315, indexed in Pubmed: 9795944.

13. Hamel $O$, Corre P, Ploteau $S$, et al. Ciliary ganglion afferents and efferents variations: a possible explanation of postganglionic mydriasis. Surg Radiol Anat. 2012; 34(10): 897-902, doi: 10.1007/s00276-012-1000-5, indexed in Pubmed: 23076729.

14. Hemmerdinger $C$, Srinivasan S, Marsh IB. Reversible pupillary dilation following botulinum toxin injection to the lateral rectus. Eye (Lond). 2006; 20(12): 1478-1479, doi: 10.1038/ sj.eye.6702366, indexed in Pubmed: 16645625.

15. Hornblass A. Pupillary dilatation in fractures of the floor of the orbit. Ophthalmic Surg. 1979; 10(11): 44-46, indexed in Pubmed: 523058.

16. Izci Y, Gonul E. The microsurgical anatomy of the ciliary ganglion and its clinical importance in orbital traumas: an anatomic study. Minim Invasive Neurosurg. 2006; 49(3): 156-160, doi: 10.1055/s-2006-944241, indexed in Pubmed: 16921456.

17. Johnston JA, Parkinson D. Intracranial sympathetic pathways associated with the sixth cranial nerve. J Neurosurg. 1974; 40(2): 236-243, doi: 10.3171/jns.1974.40.2.0236, indexed in Pubmed: 4809122.

18. Kaptanoglu E, Solaroglu I, Okutan O, et al. Lateral orbital approach to intraorbital lesions. J Ankara Med School. 2002; 24: 171-182.

19. Ko MW. Optic disc swelling: papilledema and other cause. In: Liu GT, Volpe NJ, SL G (ed.)Neuro-opthalmology: diagnosis and management: 3 ed. Elsevier, China 2018: 197-235.

20. Kushner B. How to perform superior surgery on the Inferior oblique and avoid inferior surgery on the Superior oblique. Strabismus. 2017: 221-239, doi: 10.1007/978-3-319-63019-9_13.

21. Lee JII, Kang SJ, Jeon SP, et al. Transient anisocoria during medial blowout fracture surgery. Arch Craniofac Surg. 2016; 17(3): 154-157, doi: 10.7181/acfs.2016.17.3.154, indexed in Pubmed: 28913273.

22. Lee KAh. Anisocoria after repair of blowout fracture. J Craniofac Surg. 2017; 28(5): 1289-1290, doi: 10.1097/ SCS.0000000000003597, indexed in Pubmed: 28437268.

23. McGee S. The pupils. In: Mcgee S (ed). Evidence-based physical diagnosis: 4 ed. Elsveir, Philadephia 2018: 161-183.

24. Natori $Y$, Rhoton AL. Microsurgical anatomy of the superior orbital fissure. Neurosurgery. 1995; 36(4): 762-775, doi: 10.1227/00006123-199504000-00018, indexed in Pubmed: 7596508.

25. Neuhuber W, Schrödl F. Autonomic control of the eye and the iris. Auton Neurosci. 2011; 165(1): 67-79, doi: 10.1016/j. autneu.2010.10.004, indexed in Pubmed: 21071284.

26. Sinnreich Z, Nathan H. The ciliary ganglion in man (anatomical observations). Anat Anz. 1981; 150(3): 287-297, indexed in Pubmed: 7305005.

27. Thompson HS, Kardon RH. The Argyll Robertson pupil. J Neuroophthalmol. 2006; 26(2): 134-138, doi: 10.1097/01. wno.0000222971.09745.91, indexed in Pubmed: 16845316.

28. Corbett JJ, Nerad JA, Tse DT, et al. Optic nerve sheath fenestration in pseudotumor cerebri. A lateral orbitotomy approach. Arch Ophthalmol. 1988; 106(10): 1458-1462, doi: 10.1001/archopht.1988.01060140622035, indexed in Pubmed: 3052386.

29. Yeo MS, Al-Mousa R, Sundar G, et al. Mydriasis during orbital floor fracture reconstruction: a novel diagnostic and treatment algorithm. Craniomaxillofac Trauma Reconstr. 2010; 3(4): 209-216, doi: 10.1055/s-0030-1268517, indexed in Pubmed: 22132259. 